\title{
Açık İşletme Demir Cevherleşmesinin Asit Maden Drenajı Oluşumuna Yönelik Kestirimlerinin Araştırılması (Adana/Saimbeyli)
}

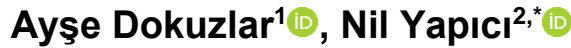 \\ ${ }^{1}$ Çukurova Üniversitesi, Fen Bilimleri Enstitüsü, Maden Mühendisliği Anabilim Dalı, 01330 Adana. \\ ${ }^{2}$ Çukurova Üniversitesi, Mühendislik Fakültesi, Maden Mühendisliği Bölümü, 01330 Adana.
}

\section{Özet}

Bu çalıșma, Adana İli, Saimbeyli İlçesi, Kaburluk Mevkiinde bulunan demir cevherleșmesinin Asit Maden Drenajı (AMD) olușumuna yönelik kestirimlerin araştırılması hakkında arazi ve laboratuvar çalışmalarını ve Asit Üretme Potansiyeli (AÜP), Nötürleştirme Potansiyeli (NP) ile ilgili statik testleri içermektedir. Bölgedeki demir cevheri oluşumu Üst Devoniyen şeyl kumtaşı-kireçtaşı ardalanmasının tabanında Orta Devoniyen dolomitik kireçtaşları içerisinde bir kapanda yerleşmiştir. Araziden alınan cevher ve yan kayaç örnekleri üzerinde jeokimyasal ve statik testler kapsamında XRF, XRD, toplam S (toplam kükürt), NP (Nötralizasyon potansiyeli), AÜP (Asit Üretim Potansiyeli), Çamur pH, fışırdama ölçümleri yapılmıș, elde edilen verilere göre örneklerin NP, NNP (Net nötralizasyon potansiyeli), AÜP, Nötürleşme potansiyel oranı (NPO=NP/AÜP) değerlendirilmiştir. Cevherleşmenin parajenezini hematit, götit, siderit ve limonit, yan kayaç parajenezini ise dolomit, kalsit ve pirit mineralleri oluşturmaktadır. Yan kayaçörneklerinde \% toplam S: 0,21-0,42, NP ( $\sum N P$ ( $\mathrm{kg} /$ ton $\left.)\right): 289,07-478,07$, Ä̈P sülfürik asit eşdeğerleri ( $\mathrm{kg} /$ ton $): 13,13-26,25$ tespit edilmiştir. NPO değerleri, 11,01-31,26 aralığında hesaplanmıștır. Cevherde yapılan analiz sonuçlarına göre: \%toplam S: 0,03-0,09, NP ( $\sum N P$ (kg/ton)): 8,07-53,16, AÜP sülfürik asit eşdeğerleri (kg/ton):1,56-5,56 tespit edilmiştir. NPO dĕgerleri ise 2,58-16,50 olarak hesaplanmıştır. NPO değerlerine göre yan kayaç ve cevherli örneklerin asit üretme potansiyeli bulunmamaktadır. Ancak, maden sahasının faaliyete geçildiği zamanlarda asit üretme potansiyel ihtimali mevcut olduğundan, kinetik testlerin bölgede maden faaliyeti başladıktan sonra yapılması önerilmektedir.

$\underline{\text { Anahtar Sözcükler }}$

Asit Maden Drenaj1, Statik Testler, Asit-Baz Hesab1, Saimbeyli/Adana Demir Cevherleşmesi

\section{Investigation of the Operations of Open Pit Iron Mineralization for Acid Mine Drainage (Adana/Saimbeyli)}

\begin{abstract}
This study includes the field and laboratory studies (statics tests related to the Acid Production Potential [APP], Neutralization Potential [NP]) to investigate the estimation for the formation of Acid Mine Drainage of an iron mineralization located in Kaburluk, Saimbeyli District, Adana Province. An iron ore formation in the studied region is located in a trap in the dolomitic limestones of the middle Devonian at the base of the shale sandstone-limestone sequences of the upper Devonian. X-ray Fluoresence (XRF), X-ray Diffraction (XRD), total sulfur (S), NP, Net Neutralization Potential (NNP), Acid Production Potential (APP), mud pH and squirting tests were carried out on the ore and other rocks samples collected from the study area within in the scope of geochemical and static tests. The NP, Net Neutralization Potential (NNP), APP, Neutralization Potential Ratio (NPR=NP/APP) values of the samples were evaluated based on the data obtained. The paragenesis of the mineralization was composed of hematite, gothite siderite and limonite, while constitutes dolomite, calcite and pyrite minerals constitute the host rock. According to the results of the analysis performed on the host rocks, \% total S: 0.21-0.42, NP ( $\sum N P$ (kg/ton)): 289.07-478.07, APP sulfuric acid equivalents ( $\mathrm{kg} /$ ton): 13, $13-26.25$ were determined. The NPR values were found to be between 11.01 -31.26. According to the results belonging to the ore samples, the following values were calculated: \% total S: 0.03-0.09, NP ( $\sum N P(\mathrm{~kg} /$ ton)): 8.07-53.16, APP sulfuric acid equivalents ( $\mathrm{kg} /$ ton): 1.56- 5.56. The NPR values of the ore sample varied 2.58 and 16.50. According to the NPR values, there was no acid producing potential of the ore-bearing samples and host rocks. However, it is recommended that kinetics test should be performed after mining activities start in the region as there is a potential to generate acid during conducting mining operations.
\end{abstract}

$\underline{\text { Keywords }}$

Acid Mine Drainage, Static Tests, Acid-Base Accounting, Saimbeyli/Adana Iron Mineralization 


\section{Giriş}

'Asitik Maden Drenaj’ terimi, sülfürlü minerallerin doğada kendiliğinden veya madencilik faaliyetleri sonucunda atmosferik oksijen ve su ile oksitlenmesi sonucu, diğer bir ifadeyle biyo/jeokimyasal reaksiyon işlemleri ile oluşan düşük pH'lı sahaları ifade etmektedir. Bu jeokimyasal döngü oluşum nedenine birçok araştırmacı katkı sağlamıştır.

Adams vd. (1965), piritin oksitlenmesi ile oluşan kimyasal aktivitenin asitsever bakterilerin ortamsal koşullarını oluşturduğunu belirtmişlerdir. Ferguson ve Erickson (1988), AMD oluşum nedenini oksidasyon reaksiyonları, nötralizasyon, maden atık özelliklerinden meydana geldiğini söylemişlerdir. Adam vd. (1996), AMD mekanizmasının maden jeolojisi, hidrojeoloji, bölgesel jeoloji çalışmalarının sonucunda ancak çözülebileceğini ifade etmişlerdir. Paktunç (1998) ise AMD oluşumunu iki faktöre bağlamış, birincil faktörleri; mineral kimyası, kayaç tip ve dokusu, tane boyutu, ikincil faktörleri; atmosferik özellikler, atık depolama yöntemleri olarak sınıflandırmıștır. Miller (1996), Morin ve Hutt (1997), White vd. (1999), Paktunç (1999), Jambor (2000), Weber vd. (2006) statik testlerin hızlı bir yöntem olduğunu ve geliştirilmesi yönünde fikir sunmuşlardır.

Madencilik faaliyetlerinden kaynaklı en ciddi problemlerden olan AMD, toprak ve yüzeysel/yeraltı su kirliliği açısından büyük sorun teşkil etmektedir. Madencilik işletme faaliyetleri ile ortaya çıkmakta ve sonrasında da yıllarca devam etmektedir. Sorunun net bir şekilde çözümü için özellikle IV. Grup madenlerde 'gelecekte oluşma ihtimali' tanımlanmasının net bir şekilde yapılması gerekmektedir. Uygun ve etkin çevresel yönetim planlaması ile sahanın Asit Maden Drenajı oluş̧urma potansiyellerinin önceden tahmin edilmesi, atığın kaynağında azaltılması, kirliliğin oluşmadan önlenmesi açısından ilk ve önemli adımı oluşturmaktadır. Bu yüzden madencilik faaliyetleri yapılırken veya maden işletmeleri tasarlanırken sadece üretim odaklı değil, üretime ek olarak atığı kaynağında azaltma ve çevresel etkileri önleme politikaları geliştirilmelidir.

Son yıllarda olası maden drenajının oluşmasını önlemek amacıyla birçok yöntem geliştirilmekte ve uygulanmakta olup maden sahasının etrafında drenaj kanalları açılması ve kireçtaşı dolgusu uygulamaları (örneğin Rötting vd. 2008; Caraballo vd. 2009; Delibalta vd. 2016), pasif ve aktif arıtma yöntemleri (örneğin Berghorn ve Hunzeker 2001; Marchand vd. 2010; Lottermoser ve Ashley 2011), cevher ve stok alanı tabanında sızma analizleri ile modelleme ve kil, jeomembran vb. kullanarak geçirimsizliğin sağlanması (örneğin Akaryalı vd. 2018; Alemdă̆ vd. 2020a,b; Gücer vd. 2020) en yaygın kullanılan yöntemleri oluşturmaktadır.

Adana ili ve ilçelerinde metal madenciliği önemli yer tutmaktadır. Özellikle $\mathrm{Pb}-\mathrm{Zn}, \mathrm{Fe}, \mathrm{Cr}, \mathrm{Al}, \mathrm{Mn}, \mathrm{Cu}, \mathrm{Au}, \mathrm{Ag}, \mathrm{Ba}$ cevherleşmeleri maden ruhsatlı olup yüksek oranda katma değer oluşturmaktadır. Cevherleşmeler ve faaliyetleri sırasında oluşabilecek tüm çevresel sorunlar Maden ve Petrol İşleri Genel Müdürlüğü (MAPEG) tarafından yönetmeliklerle denetlenmekte ve sorun yerinde halledilmektedir. Ruhsatı maden ocakların denetlenmesi amacı ile 'Maden Atıkları Yönetmeliği'nde maden atık karakterizasyonu, Sülfit-sülfür $\left(\mathrm{S}^{-2}\right)$ analizleri, statik ve kinetik testlerin yapılması açıkça belirtilmiş̧ir. Bu çalışma ile Adana ili Saimbeyli ilçesinde bulunan demir cevher oluşumunun karakteristik özelliklerinin ortaya çıkarılması ve asit kaya/maden drenajı oluşup oluşmayacağının kestirimi yapılmıştır.

Feke ve Saimbeyli ilçesi demir cevherleşmeleri literatürde önemli yer tutmakla beraber bölgesel zenginleşmelerin olası asit üretme potansiyellerinin tespiti yapılmamıştır. Önceki çalışmacılardan Ünlü vd. (1984) Saimbeyli- Feke bölgesi içerisinde bulunan demir cevherleşmelerinin sedimanter özellikte olduğunu vurgulamış, Baykul (1990) ise Saimbeyli/Aşılık bölgesi demir cevherleşmelerinin şeyl tabakaları içerisinde pirimer olarak çökelmiş piritlerin oksidasyonu sonucu oluştuğunu söylemiştir.

Saimbeyli/Kaburluk mevkiinde bulunan demir oluşumunun oluşturabileceği asit üretme potansiyelinin tespiti daha önce herhangi bir araştırmacı tarafindan incelenmemiş olup bu çalışma ile oluşum potansiyeli ortaya konmuştur. Maden işletme faaliyetinde olmadığı ve drenaj suyu bulunmadığı için cevher ve yan kayaç örneklerinin determinasyonları ve yerinde oluşturabileceği asit-baz değerlendirmeleri yapılmıştır.

Çalışma alanı Adana İl merkezine $180 \mathrm{~km}$, Saimbeyli İlçesine $22 \mathrm{~km}$ mesafede bulunmaktadır (Şekil 1). Bölge, Akdeniz kuşağı içerisine girmekte ve İç Anadolu'nun karasal iklimi etkisi altında kalmaktadır. Yaz ayları nispeten daha sıcak geçmekte kış aylarında sıcaklık düşmektedir. Uzun yıllar verilerine göre ocak ayı sıcaklık ortalamas $-3,9{ }^{\circ} \mathrm{C}$, bölgenin uzun yıllar meteorolojik verilerine göre toplam yıllık yağış ortalaması ise $362,71 \mathrm{~mm} / \mathrm{kg}-\mathrm{m}^{2}$ ' dir. Bölgede en az yağış yaz, en fazla yağış bahar ve kış aylarında görülmektedir.

\subsection{Bölgesel Jeoloji}

Çalışma alanı Üst-Orta Devoniyen yaşlı karbonatlar ve kırıntılılardan oluşan birimler içerisinde yer almaktadır (Şekil 2). Cevherleşme, Üst Devoniyen yaşlı şeyl kumtaşı-kireçtaşı ardalanmasının tabanında, Orta Devoniyen dolomitik kireçtaşları içerisinde gelişmiş olup, hidrotermal-metasomatik olarak yerleşmiştir. Metalce zengin hidrotermal çözeltiler çatlak ve kırıklar boyunca ilerleyerek bölgede çanak şeklinde yarı düzenli cevher geometrisini oluşturmuşlardır. Cevher üst zonda bulunan Üst Devoniyen yaşlı kumtaşı-şeyl ve resifal kireçtaşlarının aşınması ile yüzeyde mostra vermiştir.

Ana birimleri yaşlıdan gence doğru; Orta Devoniyen yaşlı Şafaktepe Formasyonu ve Üst Devoniyen yaşlı Gümüşali Formasyonu oluşturmaktadır (Demirtaşlı 1967). Şafaktepe formasyonu genel olarak kireçtaşından meydana gelmiş olup koyu gri, siyah; kalın tabakalı, masif ve yer yer dolomitik özelliktedir. Gümüşali formasyonu ise kumtaşı, şeyl ve kireçtaşı ardalanmalıdır. 


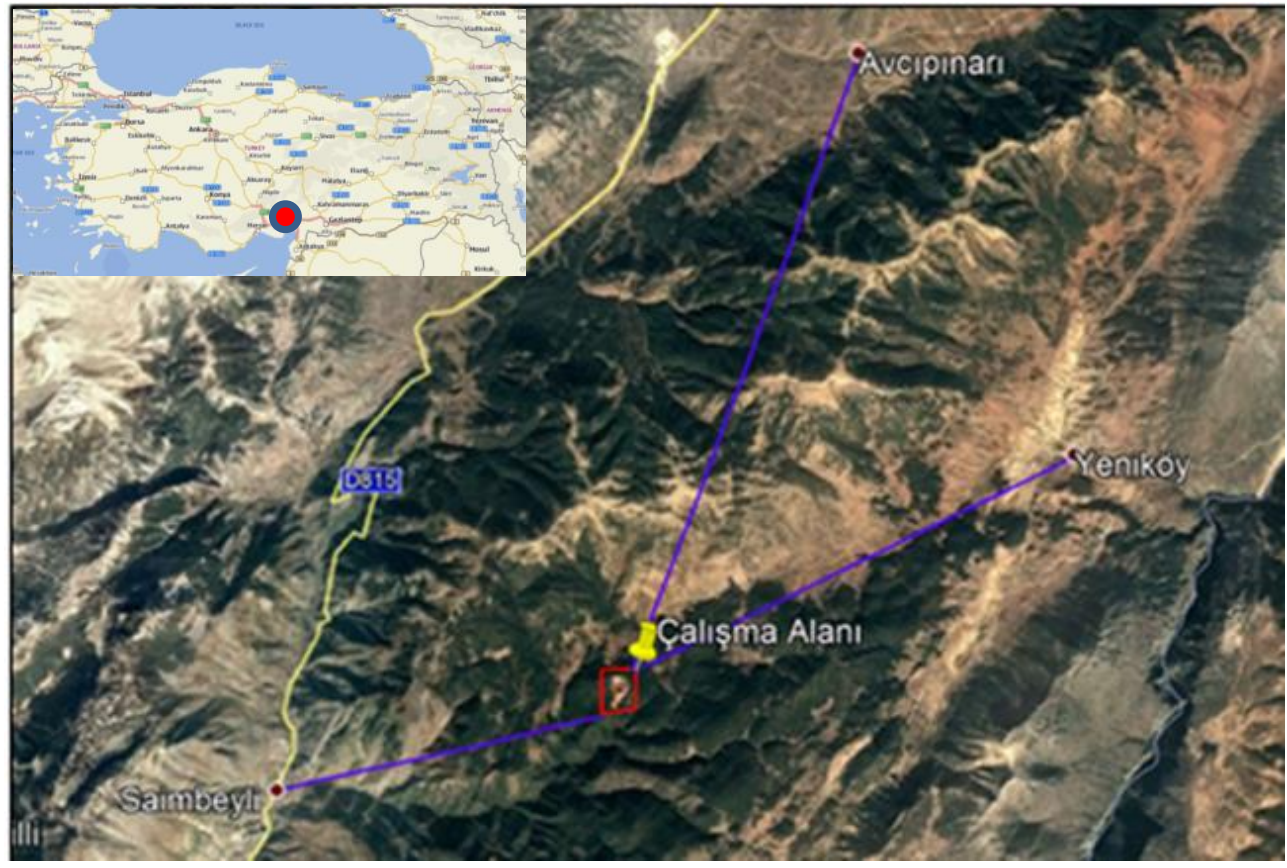

Şekil 1: Çalışma alanı ve çevresini gösterir uydu görüntüsü

\section{Materyal ve Metot}

Bu çalışma kapsamında10 adet cevher numunesi (C1 - C10) mostra veren cevherlerden, 10 adet yan kayaç numunesi (K1K10) ise yan kayaçlardan Şekil 2 ve 3'de belirtildiği gibi koordinatlı olarak alınmıştır. Örneklerin streo ve binoküler mikroskop yardımıyla petrografik tanımlamaları yapılmış, cevher ve yan kayaç mineral parajenezleri ortaya çıkarılmıştır. Ç.Ü. Merkezi Laboratuvarında; X-Işını Kırınım yöntemi (XRD) mineral analiz sonuçları 2Ø 5-85ªralığında PANalytical marka XRD kullanılarak elde edilmiştir. Ç.Ü. Maden Mühendisliği laboratuvarında; çamur pH analizleri yapılmıştır. MTA laboratuvarlarında; toplam S değer sonuçları ve Thermo ARL marka XRF cihazı kullanılarak \% oksit olarak Ca, $\mathrm{Mg}, \mathrm{Fe}, \mathrm{Si}, \mathrm{Zn}, \mathrm{K}, \mathrm{Al}, \mathrm{Mn}, \mathrm{V}, \mathrm{Ba}, \mathrm{Bi}, \mathrm{Cd}$, Co, Cr, Cu, Ti, Y, Na, Ni, P, Pb, Rb, Zr, Sn, Sr değerleri elde edilmiştir.

Asit-Baz Muhasebe (ABM) testleri ilk kez Smith vd. (1974) tarafından geliştirilmiş ve sonrasında Sobek vd. (1978) tarafından modifiye edilmiştir. Asit üretme potansiyeli yöntemi, sonrasında birçok araştırmacı tarafından geliştirilmiş ve/veya kullanılmıştır (Smith vd. 1974, 1976; Skousen vd. 1987; Lapakko 1992; Hossner ve Brandt 1997; Skousen vd. 2000; Siddharth vd. 2002; Price 2003; Lottermoser 2010; Dold 2014). İlk adımda Asit Üretim Potansiyeli ve Nötürleştirme Potansiyeli hesaplanmıştır. Fışırdama testinde $40 \mathrm{ml}$ asit miktarı ve $0,5 \mathrm{M}$ asit şiddeti uygulanmıştır. Nötürleştirme potansiyeli belirlenecek numune üzerine tatbik edilmiş asit titrasyonu sonucu bulunan değer $\mathrm{kg} \mathrm{CaCO}_{3} / \mathrm{ton}$ eşdeğeri olarak verilmiştir. Fışırdama testi sonrasında Nötürleştirme potansiyeli değerleri için laboratuvarda bir dizi işlem sonucunda numunelere muamele edilen miktardaki asit şiddetinde $\mathrm{NaOH}$ çözeltisi eklenerek pH 7 oluncaya kadar işlem devam ettirilmiş ve aritmetiksel Nötürleştirme potansiyelleri formül yardımı ile hesaplanmıştır.

Çalışma ile sülfürlü minerallerin asit üretme potansiyelleri (AÜP) (sülfür minerallerinin oksidasyonu) ile nötürleştirici noktada yer alan minerallerin (karbonatlar ve silikat minerallerinin çözünürlükleri vb.) asiti nötürleştirme kapasiteleri (NP) arasındaki denge irdelenmesi yapılmış ve yorumlanmıştır.

\section{Bulgular ve Tartışma}

\subsection{Yan Kayaç ve Cevherli Örneklerin Jeokimyası}

Araziden derlenen örneklerde gerçekleştirilen mineralojik ve kimyasal analizlere ve kalsit-dolomit mineral determinasyonuna göre yan kayaçlar, kalkerli dolomit olarak isimlendirilmiştir. Yan kayaçlarda gerçekleştirilen ana oksit kimyasal analiz sonuçları Tablo 1'de verilmiş olup XRF sonuçlarına göre $\mathrm{K}, \mathrm{V}, \mathrm{Ba}, \mathrm{Bi}, \mathrm{Cd}, \mathrm{Co}, \mathrm{Cr}, \mathrm{Cu}, \mathrm{Ti}, \mathrm{Y}, \mathrm{Na}, \mathrm{Ni}$, $\mathrm{P}, \mathrm{Pb}, \mathrm{Rb}, \mathrm{Zr}, \mathrm{Sn}, \mathrm{Sr}, \mathrm{Mo}, \mathrm{F}$ değerleri tayin sınırı altında olması sebebi ile tabloda gösterilmemiştir. 


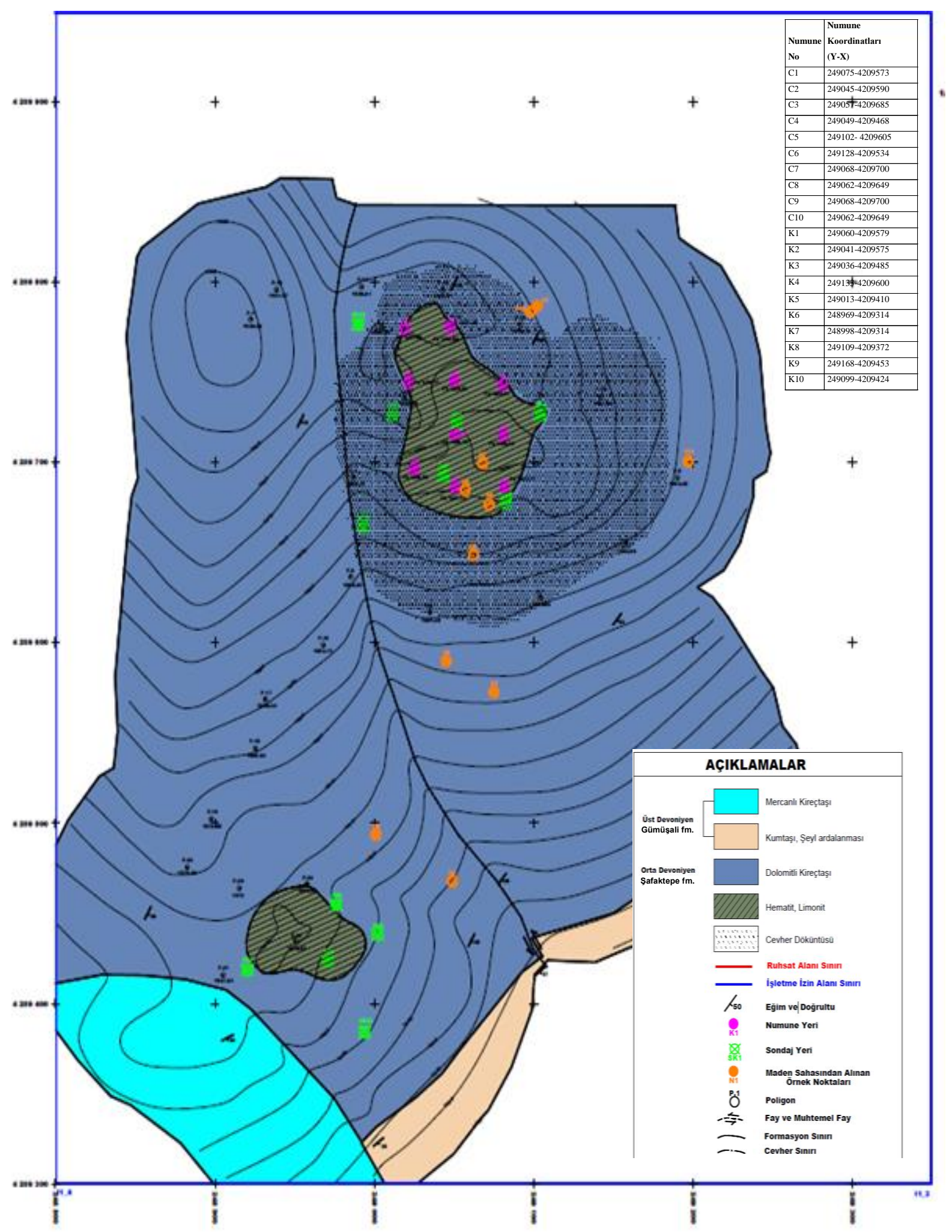

Şekil 2: Cevherleşmeye ait jeoloji haritası (Baykul 1990'dan değiştirilerek) 

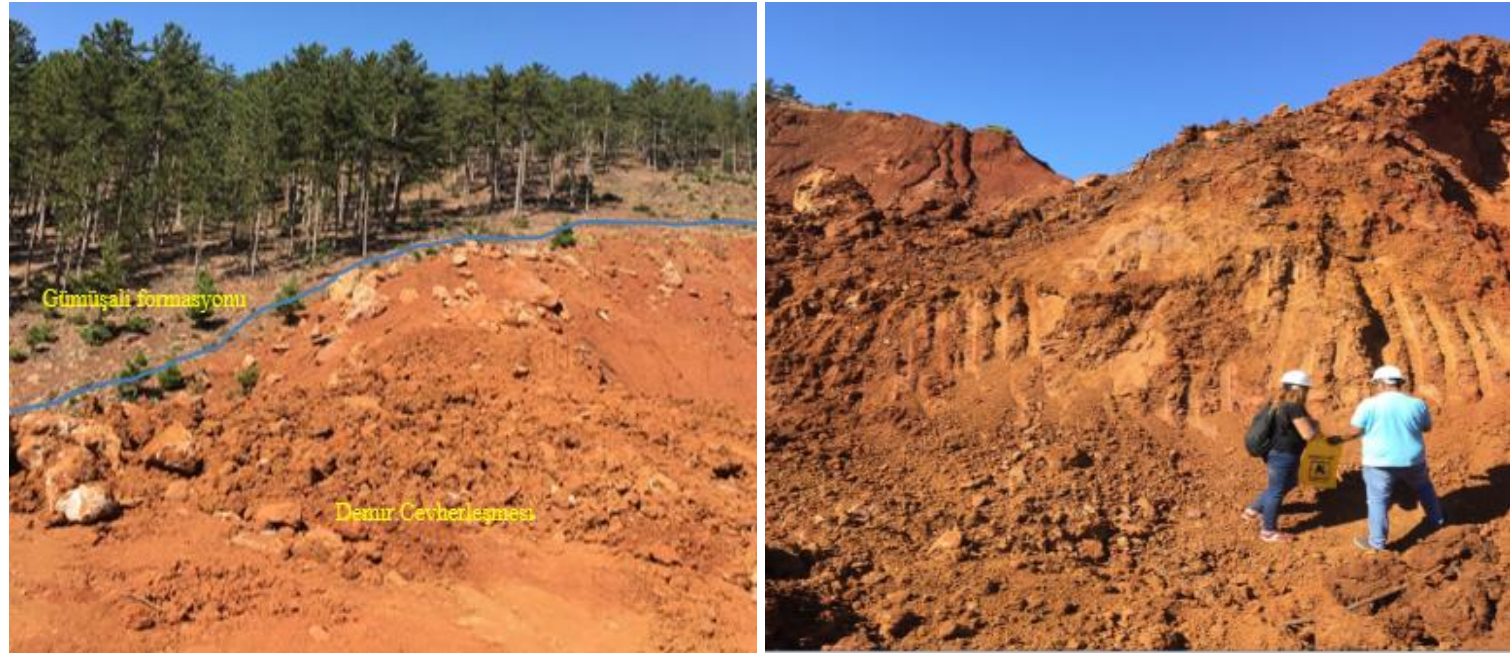

Şekil 3: Yan kayaç - cevher dokanağının ve demir cevherleşmesinin görünümü

Tablo 1: Yan kayaçların XRF analiz sonuçları

\begin{tabular}{|c|c|c|c|c|c|c|c|c|c|c|}
\hline $\begin{array}{l}\text { Element } \\
\text { (\% ăg.) }\end{array}$ & K1 & K2 & K3 & K4 & K5 & K6 & K7 & K8 & K9 & K10 \\
\hline $\mathrm{CaO}$ & 35,2 & 30,6 & 51,8 & 39,3 & 35,7 & 36,02 & 33,7 & 36,8 & 33,7 & 35,2 \\
\hline $\mathrm{MgO}$ & 15,8 & 3,0 & 2,98 & 10,0 & 14,2 & 16,3 & 14,5 & 15,4 & 16,7 & 13,5 \\
\hline $\mathrm{Al}_{2} \mathrm{O}_{3}$ & 0,20 & 2,1 & 1,4 & 0,2 & 0,8 & 0,5 & 1,8 & 3,2 & 0,4 & 2,3 \\
\hline $\mathrm{SiO}_{2}$ & 0,3 & 5,0 & 0,3 & 0,8 & 3,2 & 0,5 & 4,1 & 4,7 & 0,2 & 2,8 \\
\hline $\mathrm{MnO}$ & 0,1 & 0,1 & 0,74 & 0,1 & 0,1 & 0,1 & 0,1 & 0,74 & 0,1 & 0,74 \\
\hline $\mathrm{Fe}_{2} \mathrm{O}_{3}$ & 1,6 & 26,8 & 6,04 & 1,6 & 2,3 & 1,6 & 2,1 & 2,01 & 1,6 & 6,04 \\
\hline $\mathrm{SO}_{3}$ & $<0,01$ & 0,05 & $<0,01$ & 0,1 & $<0,01$ & $<0,01$ & $<0,01$ & $<0,01$ & $<0,01$ & 0,1 \\
\hline *A.K. & 46,5 & 31,25 & 36,08 & 39,81 & 41,03 & 44,9 & 40,8 & 31,8 & 46,9 & 38,06 \\
\hline
\end{tabular}

*A.K.: Ateşte kayıp

Yan kayaç örneklerinin ana ana oksit içerikleri değerlendirildiğinde $\mathrm{CaO}: \% 30,6-51,8, \mathrm{MgO}: \%$ 3-16,3, $\mathrm{Fe}_{2} \mathrm{O}_{3}: \% 0,1-0,74$ değerler sunmaktadır. Tablo 1'e göre cevher zonuna çok yakın bir noktadan alınan $\mathrm{K} 2\left(\mathrm{Fe}_{2} \mathrm{O}_{3}\right.$ : \%26,8) hariç olmak üzere, diğer yan kayaç örneklerinin esas olarak karbonatlı $(\mathrm{CaO}=\% 33.7-\% 51.8, n=9)$ olduğu ve toplam $\operatorname{demir}\left(\mathrm{Fe}_{2} \mathrm{O}_{3}{ }^{\mathrm{T}}\right)$ oranlarının cevher zonlarına doğru içeriklerinin yüksek olduğu gözlenmiştir. $\left(\% 1.6-6.04, \mathrm{n}=9\right.$ ). $\mathrm{SiO}_{2}$ : \% 0,2-5 aralığında tespit edilmiştir. \%5'lik değer yine cevher zonuna yakın olan K2 örneğinde görülmüştür.

Kayaç numunelerinin kızdırma kayıpları ve mineralojik incelemelere dayanan karbonat içerikleri ve $\mathrm{CaCO}_{3}-$ $\mathrm{CaMg}\left(\mathrm{CO}_{3}\right)_{2}$ içerikleri esas alınarak (Tablo 1'de görülen ateşte kayıp değerlerinin başlıca karbonat minerallerinden kaynaklandığı varsayılmıştır) toplam karbonat miktarları Tablo 2'de verilmiştir. 
Tablo 2: Kayaçta toplam karbonat değerleri

\begin{tabular}{|c|c|c|c|c|}
\hline \multirow{2}{*}{$\begin{array}{c}\text { Numune } \\
\text { No }\end{array}$} & Kuzdırma Kayıplar1 & $\mathrm{X}_{\mathrm{CaCO} 3}$ & $\mathrm{X}_{\mathrm{CaMg}(\mathrm{CO} 3) 2}$ & Toplam Karbonat \\
\cline { 2 - 5 } & $(\%)\left(1000^{\circ} \mathrm{C}^{\prime}\right.$ de 2 Saat $)$ & $(\%)$ & $(\%)$ & $(\%)$ \\
\hline K1 & 46,50 & 62,76 & 33 & 95,80 \\
\hline K2 & 31,25 & 54,56 & 6 & 60,83 \\
\hline K3 & 36,08 & 92,36 & 6 & 98,59 \\
\hline K4 & 39,81 & 70,07 & 21 & 90,98 \\
\hline K5 & 41,03 & 63,65 & 34 & 93,35 \\
\hline K6 & 44,90 & 64,22 & 32 & 98,31 \\
\hline K7 & 40,80 & 60,09 & 30 & 90,41 \\
\hline K8 & 31,80 & 65,61 & 32 & 97,82 \\
\hline K9 & 46,90 & 60,09 & 35 & 95,01 \\
\hline K10 & 38,06 & 62,76 & 28 & 90,99 \\
\hline
\end{tabular}

Yaptırılan kükürt analizi sonucu kayaç içerisinde kükürt değerleri (\% S) 0,21-0,42 aralığında tespit edilmiştir. Bu değer karbonatlı kayaç içeriğine göre yüksek bir bulgudur. Örneklerde sülfatik kükürt ve organik kükürt oranı göz ardı edilecek miktarlarda olduğu için bulunan oran piritik kükürt olarak değerlendirilmiştir. Cevherlere ait kimyasal analiz sonuçlarına göre ise; Cevher zonundan alınan 10 adet numunenin oksit değerleri sonuçları Tablo 3'de verilmiştir.

Tablo 3: Cevherli örneklerin XRF analiz sonuçları

\begin{tabular}{|c|c|c|c|c|c|c|c|c|c|c|}
\hline Element & C1 & C2 & C3 & C4 & C5 & C6 & C7 & C8 & C9 & C10 \\
\hline$\% \mathrm{CaO}$ & 0,31 & 1,53 & 2,30 & 3,01 & 1,20 & 0,79 & 1,60 & 1,09 & 2,51 & 1,10 \\
\hline$\% \mathrm{MgO}$ & 0,69 & 1,41 & 1,73 & 2,08 & 1,64 & 0,67 & 0,81 & 0,53 & 2,10 & 1,50 \\
\hline$\% \mathrm{Al}_{2} \mathrm{O}_{3}$ & 11,50 & 10,18 & 12,01 & 13,41 & 9,21 & 11,79 & 9,40 & 11,41 & 12,09 & 11,69 \\
\hline$\% \mathrm{SiO}_{2}$ & 20,50 & 19,20 & 18,10 & 22,30 & 20,10 & 16,30 & 15,80 & 17,30 & 15,60 & 17,10 \\
\hline$\% \mathrm{ZnO}$ & 0,04 & 0,14 & 0,04 & 1,40 & 0,12 & 0,10 & 0,15 & 0,14 & 1,10 & 0,70 \\
\hline$\% \mathrm{MnO}$ & 0,10 & 0,30 & 0,40 & 0,02 & 0,30 & 0,03 & 0,45 & 0,08 & 0,12 & 0,10 \\
\hline$\% \mathrm{Fe}_{2} \mathrm{O}_{3}$ & 54,40 & 52,50 & 54,60 & 47,39 & 55,25 & 56,11 & 58,23 & 56,01 & 54,50 & 57,74 \\
\hline$\% \mathrm{BaO}$ & 0,01 & 0,02 & 0,02 & 0,01 & 0,01 & 0,01 & 0,01 & 0,02 & 0,03 & 0,01 \\
\hline$\% \mathrm{~V}_{2} \mathrm{O}_{5}$ & 0,01 & 0,01 & 0,01 & 0,01 & 0,01 & 0,01 & 0,01 & 0,01 & 0,01 & 0,01 \\
\hline$\% \mathrm{Bi}_{2} \mathrm{O}_{3}$ & $<0.01$ & $<0.01$ & 0,01 & $<0.01$ & $<0.01$ & $<0.01$ & 0,01 & 0,01 & 0,01 & 0,01 \\
\hline$\% \mathrm{CdO}$ & $<0.01$ & $<0.01$ & 0,01 & $<0.01$ & $<0.01$ & $<0.01$ & 0,01 & 0,01 & 0,01 & 0,01 \\
\hline$\% \mathrm{Co}_{3} \mathrm{O}_{4}$ & 0,01 & 0,01 & 0,01 & 0,01 & 0,01 & 0,01 & 0,01 & 0,01 & 0,01 & 0,01 \\
\hline$\% \mathrm{Cr}_{2} \mathrm{O}_{3}$ & 0,01 & 0,01 & 0,01 & 0,01 & 0,01 & 0,01 & 0,01 & 0,01 & 0,01 & 0,01 \\
\hline$\% \mathrm{CuO}$ & 0,01 & 0,01 & 0,01 & 0,01 & 0,01 & $<0.01$ & $<0.01$ & $<0.01$ & $<0.01$ & $<0.01$ \\
\hline$\% \mathrm{~F}$ & $<0.01$ & $<0.01$ & 0,01 & 0,01 & 0,01 & $<0.01$ & $<0.01$ & $<0.01$ & $<0.01$ & $<0.01$ \\
\hline$\% \mathrm{~K}_{2} \mathrm{O}$ & 1,30 & 1,40 & 0,12 & 1,10 & 1,70 & 0,90 & 1,10 & $<0.01$ & $<0.01$ & 1,10 \\
\hline$\% \mathrm{TiO}_{2}$ & 0,50 & 0,40 & 0,50 & 0,40 & 0,50 & 0,40 & 0,50 & 0,40 & 0,50 & 0,40 \\
\hline$\% \mathrm{Y}_{2} \mathrm{O}_{3}$ & $<0.01$ & $<0.01$ & 0,01 & 0,01 & 0,01 & 0,01 & 0,01 & 0,01 & 0,01 & 0,01 \\
\hline$\% \mathrm{Na}_{2} \mathrm{O}$ & 0,10 & 0,20 & 0,10 & 0,20 & 0,10 & 0,20 & 0,10 & 0,20 & 0,10 & 0,20 \\
\hline$\% \mathrm{NiO}$ & 0,01 & 0,01 & 0,01 & 0,01 & 0,01 & 0,01 & 0,01 & 0,01 & 0,01 & 0,01 \\
\hline$\% \mathrm{P}_{2} \mathrm{O}_{5}$ & 0,10 & 0,10 & 0,10 & 0,10 & 0,10 & 0,10 & 0,10 & 0,10 & 0,10 & 0,10 \\
\hline$\% \mathrm{PbO}$ & 0,20 & 0,20 & 0,20 & 0,20 & 0,20 & 0,20 & 0,20 & 0,20 & 0,20 & 0,20 \\
\hline$\% \mathrm{Rb}_{2} \mathrm{O}$ & $<0.01$ & $<0.01$ & $<0.01$ & $<0.01$ & $<0.01$ & $<0.01$ & $<0.01$ & $<0.01$ & $<0.01$ & $<0.01$ \\
\hline$\% \mathrm{SO}_{3}$ & 0,16 & 0,18 & 0,01 & 0,08 & 0,01 & 0,12 & 0,10 & 0,20 & 0,18 & 0,15 \\
\hline$\% \mathrm{ZrO}_{2}$ & 0,02 & 0,02 & 0,02 & 0,02 & 0,02 & 0,02 & 0,02 & 0,02 & 0,02 & 0,02 \\
\hline$\% \mathrm{SnO}_{2}$ & $<0.01$ & $<0.01$ & $<0.01$ & $<0.01$ & $<0.01$ & $<0.01$ & $<0.01$ & $<0.01$ & $<0.01$ & $<0.01$ \\
\hline$\% \mathrm{SrO}$ & $<0.01$ & $<0.01$ & $<0.01$ & $<0.01$ & $<0.01$ & $<0.01$ & $<0.01$ & $<0.01$ & $<0.01$ & $<0.01$ \\
\hline A.K. & 9,71 & 12,10 & $\begin{array}{l}9,01 \\
, 01\end{array}$ & $\mathbf{7 , 9 8}$ & 9,10 & 8,52 & $\begin{array}{l}9,70 \\
\end{array}$ & 11,62 & 10,11 & 7,51 \\
\hline
\end{tabular}


Cevherde, $\mathrm{Fe}_{2} \mathrm{O}_{3}: \%$ 47,39-58,23, $\mathrm{CaO}: \% 0,3-3,0, \mathrm{SiO}_{2}: \%$ 15,6-22,3; $\mathrm{Al}_{2} \mathrm{O}_{3}: \% 9,2-12,1 ; \mathrm{SO}_{3}: \% 0,01-0,18$ olarak tespit edilmiştir. Kükürt analiz sonuçları \% S 0,03-0,09 aralığında olup sadece 1 örnek (C2) 0,089 değerini vermiştir. Tablo 4'deki değerlendirme parametreleri içerisinde toplam kükürt değerleri değerlendirilmiş ve $<0,05$ sınır değer üzerinde C2 örneği tespit edilmiştir (Akaryalı vd. 2018). Ateşte Kayıp değerleri 7,51-12,10 aralığındadır. CaO, MgO değerleri ve alterasyonlara bağlı olarak bu değerler normal sınırlardadır.

Cevherleşmelerde önemli rol oynayan hidrotermal fazlar çoğunlukla hareketli element birlikteliklerinin kayaçlardaki değişimlerine neden olmaktadır. Sülfid oluşumları bunlardan biridir. Demirin düşük kalkofillik derecesine göre demir sülfid minerallerinin çözünme yetenekleri oldukça fazladır. Jeokimyasal anlamda demir sülfidler çözünürken $\mathrm{Ag}, \mathrm{Cu}, \mathrm{Hg}$, $\mathrm{Pb}, \mathrm{Cd}, \mathrm{Mo}, \mathrm{Ni}, \mathrm{Co}, \mathrm{Zn}$ elementlerinin diğer bileşiklerini sülfide dönüştürerek çöktürebilmektedir. Tablo 3 'deki değerlere göre bu elementler $\mathrm{Fe}_{2} \mathrm{O}_{3}$ ile beraber sülfid oluşturabilecek konsantrasyonlarda değillerdir. Arazi gözlemlerinde de Saimbeyli cevherleşmesinde sülfid zonu tespit edilmemiştir.

\subsection{Mineralojik-Petrografik Değerlendirmeler}

Petrografik incelemelere göre yan kayaçlarda hakim mineral olarak kalsit $\left(\mathrm{CaCO}_{3}\right)$ ve dolomit $\left(\mathrm{CaMg}\left(\mathrm{CO}_{3}\right)_{2}\right.$ tespit edilmiştir. Opak mineraller fromboidal veya yarı özşekilli olarak gözlemlenmiştir. Kalsit oranı \%95-80 arasında dolomit minerali \%5-20 aralığında değişmektedir. Kalsit kristalleri basınç ikizleri ve rengi, dolomit kristalleri belirgin dilinim yüzeyleri ve röliefleri ile tanımlanmıştır.

Çekilen X- Işını Difraksiyon (XRD) mineralojik analiz patern yorumlarına göre pikler kalsit $\left(\mathrm{CaCO}_{3}\right)$, dolomit, pirit $\left(\mathrm{FeS}_{2}\right)$, ankerit $\mathrm{Ca}\left(\mathrm{Fe}^{2+}, \mathrm{Mg}\right)\left(\mathrm{CO}_{3}\right)_{2}$ dir ve Şekil 4' te kayaca ait mineral analizleri verilmiştir.
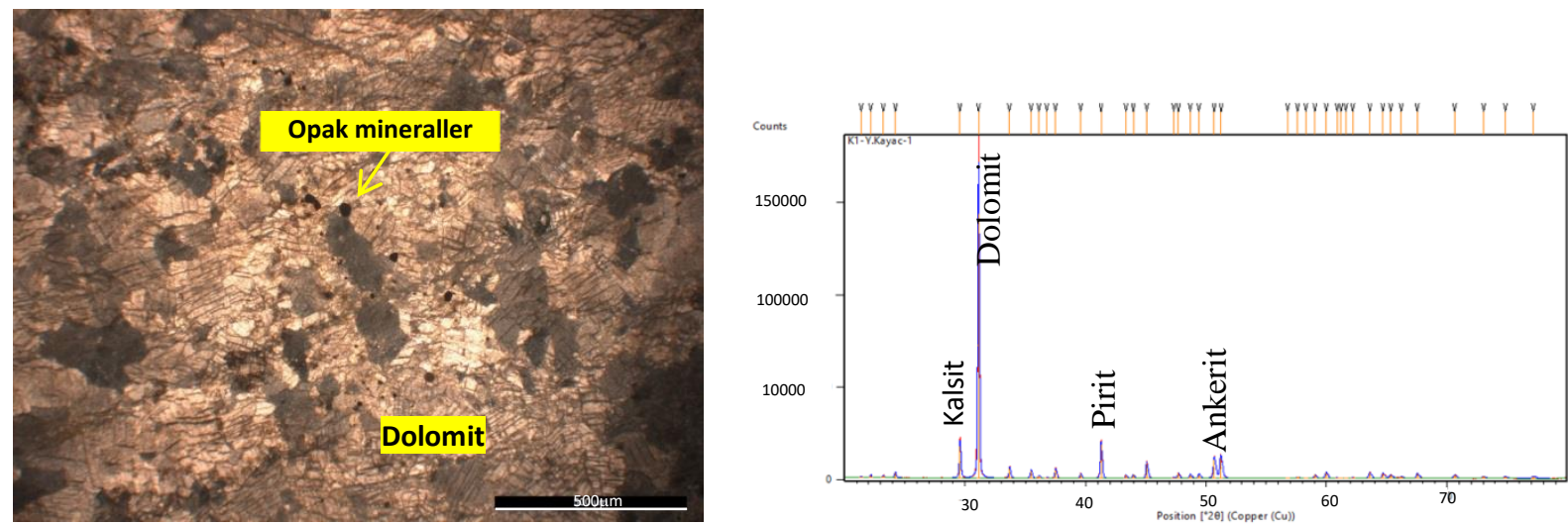

Şekil 4: Ince kesitte dolomit, kalsit ve opak mineralleri (pirit) ve XRD patern görünümü

Parlak kesit incelemeleri sonucu ana minaraller hematit $\left(\mathrm{Fe}_{2} \mathrm{O}_{3}\right)$, götit $\left(\mathrm{HFeO}_{2}-\mathrm{FeO}(\mathrm{OH})\right)$, ankerit $\mathrm{Ca}\left(\mathrm{Fe}^{2+}, \mathrm{Mg}\right)$ $\left(\mathrm{CO}_{3}\right)_{2}$ olarak tespit edilmiştir. XRD piklerine göre ise mineraller hematit, götit, ankerit, kuvars $\left(\mathrm{SiO}_{2}\right)$ dır. Şekil 5' te cevhere ait mineral analizleri verilmiştir.
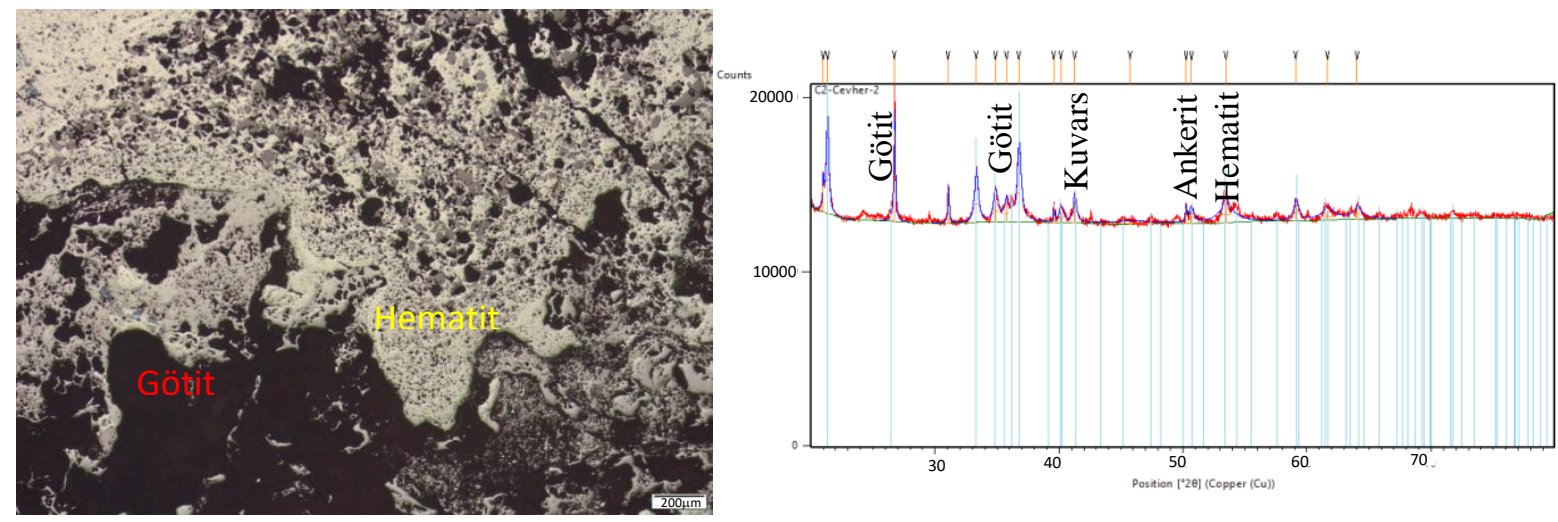

Şekil 5: Cevher parlak kesit ve XRD patern görünümü 


\subsection{Macun pH Değerlendirmeleri}

Çamur pH'1 4'ün altında olan kayaçlar asit toksik kabul edilmekte ve \% 0,5’ten fazla sülfür içeren kayaçlar kayda değer potansiyel asit üretebilmektedir (örneğin Price vd. 1997; Miller ve Murray 1988). Çözeltinin pH'1 kullanılan saf suyun pH'ından büyük olması gerekmektedir. Deneylerde kullanılan saf su pH'1 5,6-5,9 değer aralığında ölçülmüştür. Çalışma alanından alınan cevherli toprak örneklerinden yapılan 10 adet örnek için çamur $\mathrm{pH}$ değer sonuçları 7,6-8,2 arasında tespit edilmiştir. Bu değerler $\mathrm{pH}>7$ yorumuna göre asit üretme potansiyellerinin düşük olduğuna işaret etmektedir (Tablo 4) (Alemdağ vd. 2020a).

Tablo 4: Statik test değerlendirme tablosu

\begin{tabular}{|c|c|c|c|}
\hline Referans & NPO & NNP & Macun pH \\
\hline Price vd. (1997) & $\begin{array}{l}<1, \text { asit üretir (yeterli nötrleştirme } \\
\text { kapasitesine sahip olmayan) } \\
\text { 1-2, potansiyel asit üreticisi } \\
\text { 2-4, düşük potansiyel asit } \\
\text { üreticisi } \\
>4, \text { asit üretmez (yeterli } \\
\text { nötrleştirme kapasitesine sahip) }\end{array}$ & & $\begin{array}{l}\mathrm{pH}<4, \text { Acid } \\
\mathrm{pH}>7 \text {, Neutral }\end{array}$ \\
\hline Soregaroli ve Lawrence ( 1998) & $\begin{array}{l}<1, \text { potansiyel asit üreticisi } \\
1-3 \text {, belirsiz bölge (asit üretme } \\
\text { potansiyeli zayıf) } \\
>4 \text {, asit üretmez }\end{array}$ & & \\
\hline Brodie vd. (1991) & $\begin{array}{l}<1, \text { asit üretir } \\
1-3(\mathrm{I}<\mathrm{NP} / \mathrm{AP}<3) \text {, belirsiz bölge } \\
>3 \text {, asit üretmez }\end{array}$ & & \\
\hline Ferguson ve Morin (1991) & & $\begin{array}{l}<-20 \text {, potansiyel asit üreticisi } \\
-20<\mathrm{NNP}<20 \text {, belirsiz bölge } \\
>20 \text {, asit üretmez }\end{array}$ & \\
\hline Sobek vd. (1978) & & $<-5$, asit üretir & \\
\hline Day (1989) & & $\begin{array}{l}<10 \text {, asit üretir } \\
>10, \text { asit üretmez }\end{array}$ & \\
\hline
\end{tabular}

\subsection{Asit-Baz Muhasebesi (ABM)}

Çalışma alanından alınan karbonatlı kayaç ve demir cevher örneklerinden elde edilen AÜP, NP, Toplam S, Çamur pH değerleri ABM yorumlama tablosunda verilmiştir (Tablo 5). Şekil 6-8 de, Tablo 5'deki değerler kullanarak NNP- Macun pH, (NP/AÜP), Sülfid-NPO grafikleri çizilmiş ve yorumlanmıştır. Macun pH değerleri kullanılarak Net NP (NP/AÜP) yorum tablosuna göre cevher örnekleri 'Belirsiz Bölge ve Potansiyel Asit Üretmeyen Bölge'de çıkarken, yan kayaç örnekleri 'Potansiyel Asit Üretmeyen' bölgede çıkmaktadır (Şekil 6). Macun pH değerlerine göre çizilen yorum tablosunda gözlenen belirsiz olan durumun değişebileceği düşünülerek bölgedeki cevherleşmelerde kinetik testlerin de yapılması gereklidir.

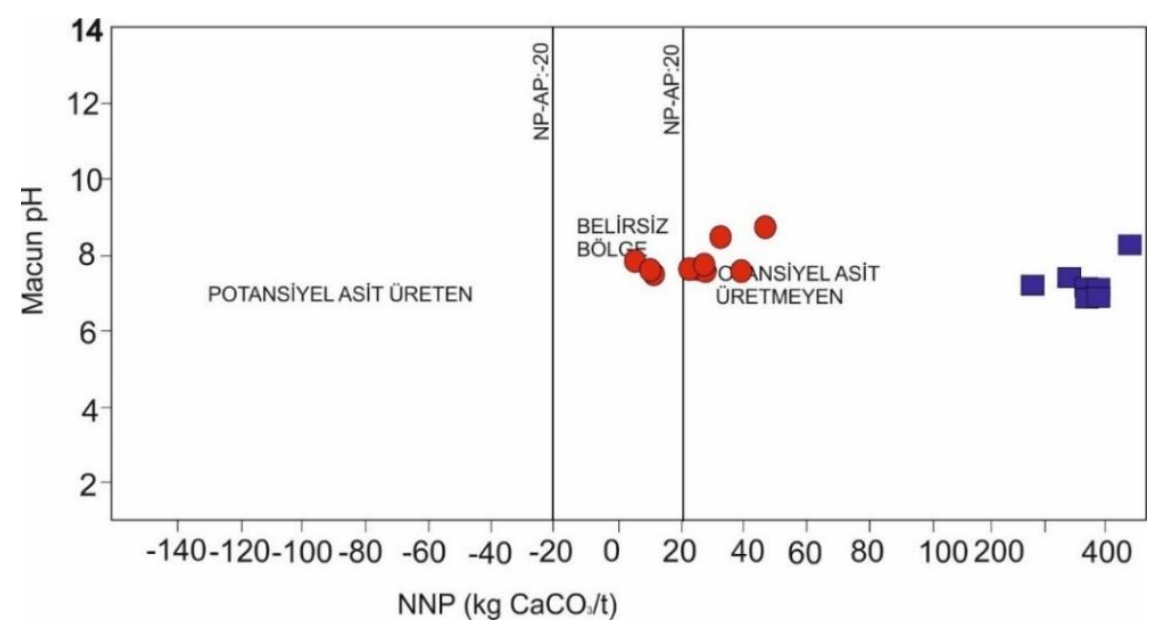

Şekil 6: Örneklerin NNP- Macun pH diyagramı (Ferguson ve Morin 1991: kırmızı daire semboller cevherli örnekleri, mavi kare semboller ise yan kayaçları temsil etmektedir) 
Tablo 5: Örneklerin asit-baz hesabı test sonuçları

\begin{tabular}{|c|c|c|c|c|c|c|c|}
\hline $\begin{array}{c}\text { Numune } \\
\text { No }\end{array}$ & $\begin{array}{c}\text { F1şırdama } \\
\text { Hizı } \\
\text { (0=Yok, } \\
\text { 1=Hafif, } \\
\text { 2=Orta, } \\
\text { 3=Kuvvetli) }\end{array}$ & $\% \mathrm{~S}$ & $\begin{array}{c}\text { Çamur } \\
\mathrm{pH}\end{array}$ & $\begin{array}{c}\mathrm{AÜP} \\
\mathrm{kgCaCO}_{3} / \text { ton }\end{array}$ & $\begin{array}{c}\mathrm{NP} \\
\sum \mathrm{NP}(\mathrm{kg} / \text { ton }) \\
\mathrm{kgCaCO}_{3} / \text { ton }\end{array}$ & $\begin{array}{c}\text { Net NP } \\
(\mathrm{NP}-\mathrm{AÜP}) \\
\mathrm{kgCaCO}_{3} / \text { ton }\end{array}$ & $\begin{array}{c}\mathrm{NPO} \\
(\mathrm{NP} / \mathrm{AÜP}) \\
\mathrm{kgCaCO}_{3} / \text { ton }\end{array}$ \\
\hline $\mathrm{C} 1$ & 0 & 0,05 & 8,1 & 3,13 & 8,07 & 4,94 & 2,58 \\
\hline $\mathrm{C} 2$ & 0 & 0,09 & 7,9 & 5,56 & 28,53 & 22,97 & 5,13 \\
\hline C3 & 0 & 0,05 & 8,2 & 3,31 & 41,27 & 37,96 & 12,47 \\
\hline $\mathrm{C} 4$ & 0 & 0,06 & 8,1 & 3,44 & 53,16 & 49,72 & 15,45 \\
\hline $\mathrm{C} 5$ & 0 & 0,06 & 8,1 & 3,56 & 25,59 & 22,03 & 7,19 \\
\hline C6 & 0 & 0,03 & 8,0 & 1,56 & 14,42 & 12,86 & 9,24 \\
\hline $\mathrm{C} 7$ & 0 & 0,08 & 8,0 & 5,25 & 26,53 & 21,28 & 5,05 \\
\hline $\mathrm{C} 8$ & 0 & 0,05 & 7,9 & 3,19 & 18,12 & 14,93 & 5,68 \\
\hline C9 & 0 & 0,05 & 8,2 & 2,81 & 46,29 & 43,48 & 16,50 \\
\hline $\mathrm{C} 10$ & 0 & 0,03 & 8,2 & 1,75 & 23,63 & 21,88 & 13,50 \\
\hline $\mathrm{K} 1$ & 2 & 0,25 & 7,6 & 15,63 & 403,28 & 387,65 & 25,80 \\
\hline $\mathrm{K} 2$ & 2 & 0,42 & 7,8 & 26,25 & 289,07 & 262,82 & 11,01 \\
\hline K3 & 2 & 0,25 & 7,9 & 15,63 & 478,07 & 462,44 & 30,59 \\
\hline K4 & 2 & 0,41 & 7,8 & 25,63 & 407,29 & 381,66 & 15,89 \\
\hline K5 & 2 & 0,21 & 7,6 & 13,13 & 410,44 & 397,31 & 31,26 \\
\hline K6 & 2 & 0,40 & 7,6 & 25,00 & 407,87 & 382,87 & 16,31 \\
\hline K7 & 2 & 0,35 & 7,7 & 21,88 & 381,79 & 359,91 & 17,45 \\
\hline K8 & 2 & 0,25 & 7,8 & 15,63 & 414,89 & 399,26 & 26,54 \\
\hline K9 & 2 & 0,42 & 7,8 & 26,25 & 395,35 & 369,10 & 15,06 \\
\hline K10 & 2 & 0,30 & 7,9 & 18,75 & 389,72 & 370,97 & 20,79 \\
\hline
\end{tabular}

Nötürleşme potansiyel oranı (NPO) asit maden oluşumunda tespit edilmesi gereken en önemli parametredir. Maden atık yönetmeliği EK-4 B maddesi "İnert Maden Atıklarının Belirlenmesi” 2. maddesinde geçen "Maden atığının sülfür $\left(\mathrm{S}^{-2}\right)$ miktarı en fazla \% 0,1 olmalıdır. Bununla birlikte; maden atı̆̆ının sülfür $\left(\mathrm{S}^{-2}\right)$ miktarı \% 0,1 ile $\% 1$ arasında ise, nötrleştirme potansiyeli (NP) ile asit potansiyeli (AP) arasındaki oran (NP/AP) şeklinde tanımlanan statik teste dayalı olarak belirlenen değerin 3'ten büyük olması gerekmektedir. Sobek vd. (1978), Brodie vd. (1991), Lapakko (2002)'e göre çizilen diyagrama göre tüm örnekler, NPO>3 durumunda olduğu için diyagramın 'asit üretmeyen' bölgesine düşmektedir (Şekil 7). Sülfid-Sülfür ve NPO (NP/AÜP) değerlerine göre ise tüm örnekler 'Asit Üretmeyen’ bölgede yer almıştır (Şekil 8).

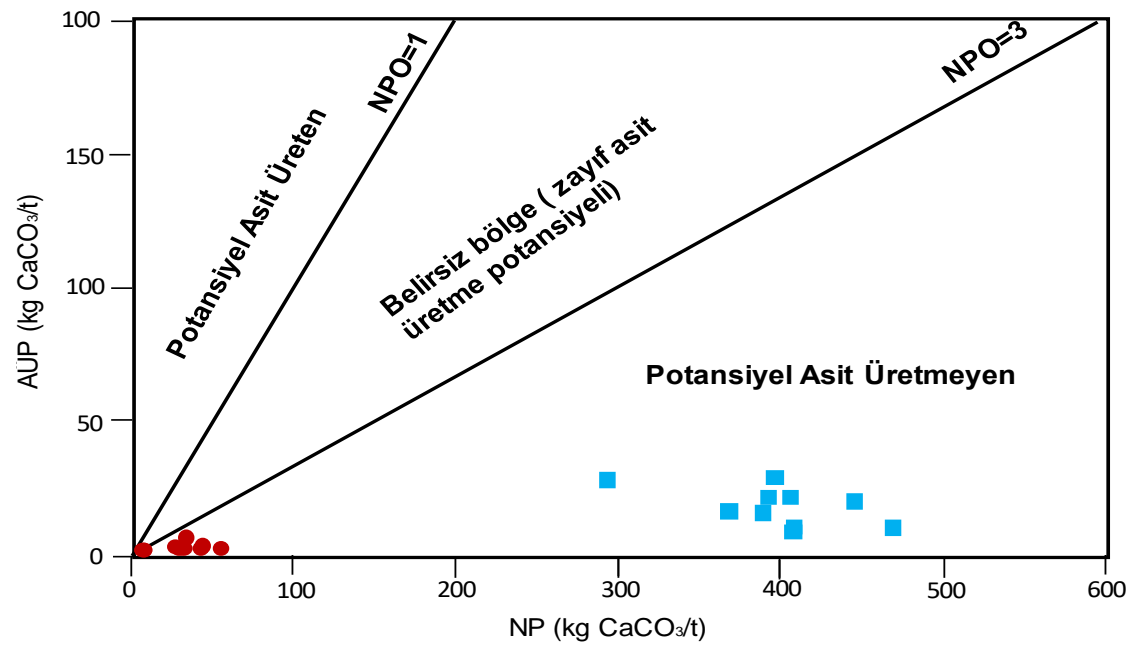

Şekil 7: NP-AÜP değerlerine göre ABH yorum grafiği (Sobek vd. 1978; Brodie vd. 1991; Lapakko 2002: kırmızı daire semboller cevherli örnekleri, mavi kare semboller ise yan kayaçları temsil etmektedir). 


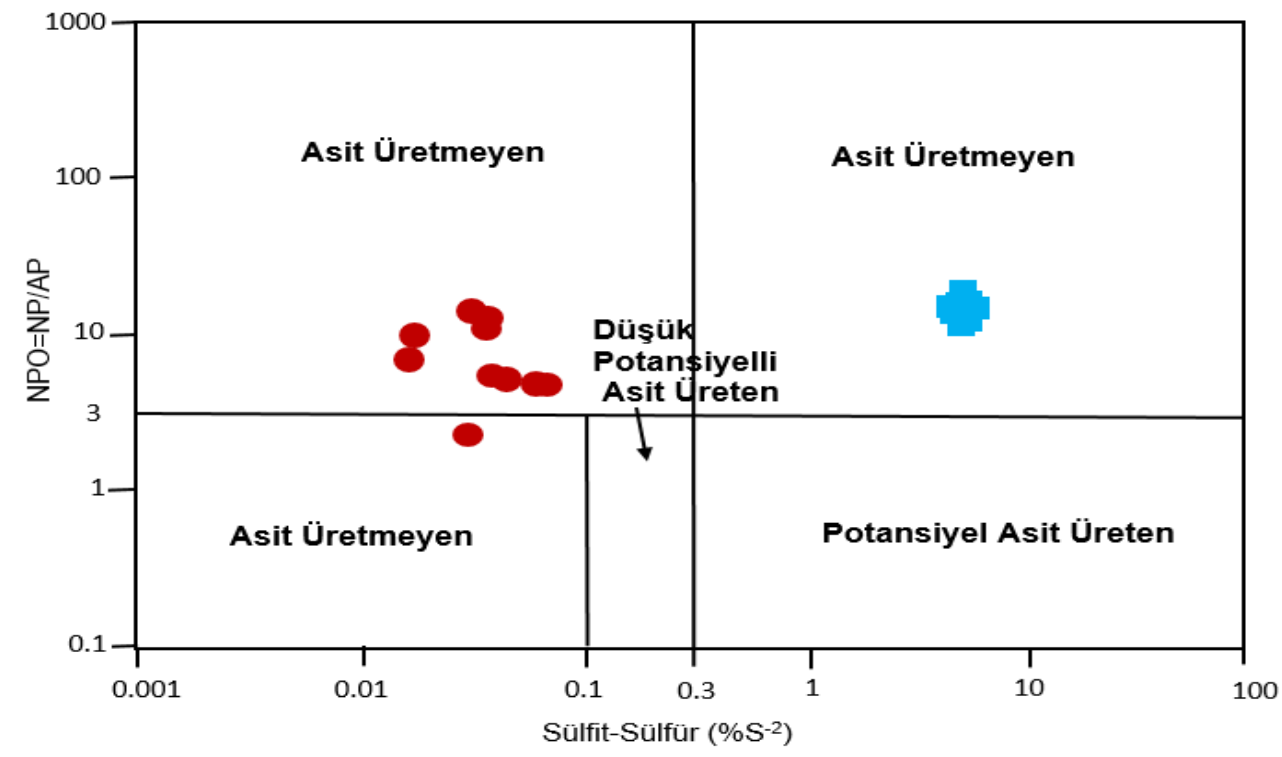

Şekil 8: Örneklerin Sülfid-Sülfür ve NPO diyagramları (Sobek vd. 1978; Brodie vd. 1991; Price vd. 1997: kırmızı daire semboller cevherli örnekleri, mavi kare semboller ise yan kayaçları temsil etmektedir).

\section{Sonuçlar}

Çalışma, Adana İli, Saimbeyli İlçesi, Kaburluk Mevkiinde bulunan demir cevherleşmesinin AMD oluşumuna yönelik kestirimlerin araştırılması hakkında arazi ve laboratuvar çalışmalarını içermektedir. Elde edilen sonuçlara göre;

- Cevherleşme, Üst Devoniyen şeyl kumtaşı-kireçtaşı ardalanmasının tabanında bu formasyonların oluşturdukları bir kapanda dolomitik kireçtaşları içinde hidrotermal- metasomatik olarak yerleşmiş olup, karbonatlı birimler içerisinde merceksel olarak yataklanmıştır. Yüzeyde oksidasyon zonu ile oldukça belirgin bir görünüm sunmaktadır.

- Örneklerin toplam karbonat miktarı ortalaması \%91,2 \% toplam kükürt (S) 0,21-0,42 ve AÜP (kg/ton) değerleri 13,13-26,25 aralığında tespit edilmiştir. NP $\sum \mathrm{NP}(\mathrm{kg} / \mathrm{ton})$ 289,07-478,07 aralığında hesaplanmıştır.

- Kayaç, $\mathrm{CaO}$ : \%30,6-51,8, MgO:\% 3-16,3 içeriğine ve mineral analizlerine göre dolomitli kireçtaşı olarak isimlendirilmiştir.

- Cevherli örneklerin ana parajenezini hematit, götit, siderit ve limonit oluşturmakta, gang minerali olarak kalsit ve az oranda kuvars gözlenmektedir.

- Cevherde \%toplam kükürt (S) 0,03-0,09 ve AÜP (kg/ton) değerleri 1,56-5,56 aralığında tespit edilmiştir. NP $\sum \mathrm{NP}(\mathrm{kg} /$ ton) 8,07-53,16 aralığında hesaplanmıştır. NPO değerleri kayaçta 11,01-31,26, cevherde 2,58-16,50 arasında bulunmuştur.

- Macun pH ve NNP değerlerine göre cevherli örnekler 'Belirsiz Bölge ve Potansiyel Asit Üretmeyen Bölge'de yer alırken, yan kayaç örnekleri ‘Potansiyel Asit Üretmeyen' bölgede yer almıştır.

- NP-AÜP içeriklerine göre tüm örnekler NPO $>3$ olup, 'asit üretmeyen' bölgeye düşmüş̧ür.

- Örneklerin Sülfid-Sülfür ve NPO değerlerine göre tüm örnekler 'Asit Üretmeyen' bölgede yer almıştır.

İlerleyen yıllar cevherin ve yan kayacın, hammadde alım esnasında ve stoklanma zorunluluğu doğabilecek durumlarda atmosferik sularla açık alanda asit üretme potansiyeli bulunma ihtimali mevcuttur. Bu durumda kinetik testlerin bölgede maden faaliyeti başladıktan sonra yapılması önerilmektedir.

\section{Teşekkür}

Bu makale Ayşe DOKUZLAR'a ait Çukurova Üniversitesi, Fen Bilimleri Enstitüsü yüksek lisans tezinden türetilmiştir.

\section{Kaynaklar}

Adam K., Kourtis A., Gazea B.,Kontopoulos, A., (1996), Comparison of static test techniques for the prediction of acid rock drainage in polymetallic sulphide mines, Engineering Foundation Conference in the Mining and Mineral Processing Industries, Italy, ss.121127.

Akaryalı E., Gücer M.A., Alemdağ S., (2018), Atık barajı rezervuarı ve cevher stok alanlarında asit maden drenajı (amd) oluşumunun değerlendirilmesi: Gümüşhane Örneği, Doğal Afetler ve Çevre Dergisi, 4(2), 192-209. 
Alemdağ S., Akayalı E., Gücer M.A., (2020a), Flotasyon tesis atıklarının asit üretme potansiyeli ve kirliliğin önlenmesi, Gümüşhane, KD Türkiye, Yerbilimleri, 41(1), 56-85.

Alemdağ S., Akaryalı E., Gücer M.A., (2020b), Prediction of mine drainage generation potential and the prevention method in the Gümüşöy (Kütahya) mineralization area, NW-Turkey. Journal of Mountain Science, 17(10), 2387-2404.

Baykul A., (1990), Aşılık (Saimbeyli-Adana) Demir yatağının metalojenik incelemesi, Yüksek Lisans Tezi, Çukurova Üniversitesi, Fen Bilimleri Enstitüsü, Adana.

Berghorn G.H., Hunzeker G.R., (2001), Passive treatment alternatives for remediating abandoned-mine drainage. Remediation 11, 111-127.

Brodie M.J., Broughton L, M., Robertson A., (1991), A conceptual rock classification system for waste management and laboratory method for ard prediction from rock piles, Second Internetional Conference on the Abatement of Acid Drainage, Vol:3 Montreal, Quebec, September 16-18, MEND Program Ed- Quebec Mining Association, Otawa, ss. 119-135.

Caraballo M.A., Rötting T.S., Macías F., Nieto J.M., Ayora C., (2009), Field Multi-step limestone and mgo passive system to treat acid mine drainage with high metal concentrations, Applied Geochemistry, 24, 2301-2311.

Day S.J., (1989), Comments after presentation of: A practical approach to testing for acid mine drainage in the mine planning and approval process, Thirteenth Annual British Columbia Mine Reclamation Symposium, June 7-9, Vernon, British Columbia.

Delibalta M.S., Uzal N., Lermi A., (2016), Acid mine drainage and rehabilitation in Ilgin Lignite Mines Lakes. Nigde University Journal of Engineering Sciences, 5(1), 73-82.

Demirtaşlı E., (1967), Pınarbaşı-Sarız-mağara civarının jeoloji raporu, MTA Enst. Raporu, Rapor No: 1935, 129ss.

Dold B., (2014), Evolution of acid mine drainage formation in sulphidic mine tailings, Minerals, 4(2), 621-641.

Ferguson K.D., Erickson P.M., (1988), Pre-mine prediction of acid mine drainage. in: dredged material and mine tailings. Edited by Dr. Willem Salomons and Professor Dr. Ulrich Forstner. Copyright by Springer-Verlag Berlin Heidelberg.

Ferguson K.D., Morin, K.A., (1991), The prediction of acid rock drainage-lessons from the database. Proceedings of the 2nd ICARD içinde, vol. 1-4 Montréal, QC, Canada, ss.83-106.

Gücer M.A., Alemdağ S., Akaryalı E., (2020), Assessment of acid mine drainage formation using geochemical and static tests in Mutki (Bitlis, SE Turkey) Mineralization Area. Turkish Journal of Earth Sciences, 29(7), 1189-1210.

Heier K.S., Adams J.A.S., (1965), Concentration of radioactive elements in deep crustal material, Geochimica et Cosmochimica Acta, 29(1), 53-61.

Hossner L.R., Brandt J.E., (1997), Acid/base account and minesoils: A Review, Proceedings of 14th Annual Meeting of the ASSMR. America Society of Mining and Reclamation, ss.128-140.

Jambor J.L., Dutrizac, J.E., Chen T.T., (2000), Contribution of specific minerals to the neutralization potential in static tests, In Proceedings of Fifth International Conference on Acid Rock Drainage; Society for Minining, Metallurgy, and Exploration, Littleton, CO, USA, ss.551-565.

Lapakko K., (1992), Characterization and Static Testing of Ten Gold Mine Tailings. Proceedings America Society of Mining and Reclamation, ss.370-384, doi: 10.21000/JASMR92010370.

Lapakko K., (2002), Metal mine rock and waste characterization tools: An overview, Mining, Minerals and Sustainable Development, No:67, International Institute for Environment and Development (IIED), England, 28ss.

Lottermoser B.G., (2010), Mine wastes: Characterization, Treatment and Environmental Impacts, Third Edition. Springer, Berlin, Heidelberg, 400ss.

Lottermoser B.G., Ashley P.M., (2011), Trace element uptake by Eleocharis equisetina (spike rush) in an abandoned acid mine tailings pond, northeastern Australia: Implications for land and water reclamation in tropical regions. Environmental Pollution, 159, 30283035.

Marchand L., Mench M., Jacob D.L., Otte M.L., (2010), Metal and metalloid removal in constructed wetlands, with emphasis on the importance of plants and standardized measurements: a review. Environmental Pollution, 158, 3447-3461.

Miller S.D. (1996), Advances in Acid Mine Drainage: Prediction and Implication for Risk Management, Proceeding of the 3rd International and 21st Annual Minerals Council of Australia Environmental Workshop, 14-18 October, Newcastle, New South Wales, ss.149-157.

Miller S.D., Murray G.S., (1988), Application of acid base analysis to wastes from base metal and precious metal mines, Proceedings America Society of Mining and Reclamation, ss.29-32, doi: 10.21000/JASMR88010029.

Morin K.A., Hutt N.M., (1997), Environmental geochemistry of minesite drainage; Practical theory and case studies, MDAG Pub, Canada, 333ss.

Paktunç D., (1998), Characterization of mine wastes for prediction of acid mine drainage. Proceeding: Acid Mine Drainage Seminar/ Workshop, Conservation and Protection Environment, Ontario, Canada, ss.1-45.

Paktunç A. D., (1999), Minerological constrains on the determination of neutralization potential and prediction of acid mine drainage, Environmental Geology, 38, 82-84.

Price W.A., Errington J., Koyanagi V., (1997), Guidelines for the prediction of acid rock drainage and metal leaching for mines in British Columbia: part I. General Procedures and Information Requirements. Proc, 4th ICARD, Natural Resources Canada, Ottawa, 1, 1-14.

Price W.A., (2003), Challenges posed by metal leaching and acid rock drainage and approaches used to address them, Jambor, J.L., Blowes, D.W., Ritchie, A.I.M. (eds.), Environmental aspects of mine wastes. mineralogical association of Canada, Short Course Series, 31, ss.15-30.

Rötting T.S., Caraballo M.A., Serrano J.A., Ayora C., Carrera J., (2008), Field application of calcite dispersed alkaline substrate (calcite-DAS) for passive treatment of acid mine drainage with high Al and metal concentrations, Applied Geochemistry, 23, 16601674.

Soregaroli B.A, Lawrence R.W., (1998), Update on waste characterisation studies, Proceedings mine design, operations and closure conference, Polson, MT, USA.

Siddharth S., Jamal A., Dhar B.B., Shukla R., (2002), Acid-base accounting: a geochemical tool for management of acid drainage in coal mines, Mine Water and the Environment, 21, 106-110. 
Skousen J.G., Sencindiver J.C., Smith R.M., (1987), A review of procedures for surface mining and reclamation in areas with acidproducing materials, EWRC 871, West Virginia University, Morgantown, WV, 40ss.

Skousen J.G., Sexstone A., Ziemkiewicz P.F., (2000), Acid mine drainage control and treatment, Hartfield, J.L., Volenec, J.G., Dick, W.A. (eds), Reclamation of drastically disturbed lands. American Society of Agronomy and American Society for Surface Mining and Reclamation. Agronomy No. 41, ss.131-169.

Smith, R.M., Grube, W.E.Jr., Arkele, T.Jr., Sobek, A.A., (1974), Mine spoil potentials for soil and water quality. West Virginia University. EPA-670/2-74-070, 303ss.

Smith R.M., Sobek A.A., Arkle T., Sencindiver J.C., Freeman J.R., (1976), Extensive overburden potentials for soil and water quality, EPA-600/2-76-184, USEPA, Cincinnati, OH.

Sobek A.A., (1974), Mine spoil potentials for soil and water quality, West Virginia University, EPA-670/2-74-070, 303ss.

Sobek A.A., Schuller W.A., Freeman J.R., Smith R.M., (1978), Field and laboratory methods applicable to overburdens and minesoils, EPA-600/2-78-054. US Govt Printing Office, Washington, DC., USA.

Ünlü T., Yıldırım M., Öztürk M., Dağlıoğlu C., Kırıkoğlu G., Hasarı M., (1984), Feke-Mansurlu yöresi demir yataklarının oluşum modeli hakkında bir yaklaşım, MTA Maden Etüt Demir İzleme Destek 50225/1104, 3, Ankara.

Weber P. A., Hughesu J. B., Conner L. B., Lindsay P., Smart R. C., (2006), Short-term acid rock drainage characteristics determined by paste pH and kinetic NAG testing: Cypress Prospect, Proceeding from the 7th international conference on acid rock drainage, Missouri, ss.2289-2310, doi: 10.21000/JASMR06022289.

White W. W., Lapokko K. A., Cox R. L., (1999), Static-test methods most commonly used to predict acid mine drainage: Practical guidelines for use and interpretation. In the environmental geochemistry of ore deposits. Part A: Processes, Techniques, and Health Issues; Reviews in Economic Geology; Plumlee, G.S., Logsdon, M.J., Eds.; Society of Economic Geologists: Littleton, CO, USA, ss.325-338. 